\title{
Prevalence and degree of hearing loss among males in Beaver Dam cohort: Comparison of veterans and nonveterans
}

\author{
Richard H. Wilson, PhD; ${ }^{1-2^{*}}$ Colleen M. Noe, PhD; ${ }^{1-2}$ Karen J. Cruickshanks, PhD; ${ }^{3-4}$ Terry L. Wiley, PhD; \\ David M. Nondahl, MS $^{3}$ \\ ${ }^{1}$ Department of Veterans Affairs Medical Center, Mountain Home, TN; ${ }^{2}$ Department of Audiology and Speech- \\ Language Pathology and Department of Surgery, East Tennessee State University, Johnson City, TN; Departments \\ of ${ }^{3}$ Ophthalmology \& Visual Sciences and ${ }^{4}$ Population Health Sciences, University of Wisconsin, Madison, WI; \\ ${ }^{5}$ Department of Communicative Disorders, University of Wisconsin, Madison, WI
}

\begin{abstract}
The Epidemiology of Hearing Loss Study (EHLS) conducted in Beaver Dam, Wisconsin, was a population-based study that focused on the prevalence of hearing loss among 3,753 participants between 1993 and 1995. This article reports the results of several auditory measures from 999 veteran and 590 nonveteran males 48 to 92 years of age included in the EHLS. The auditory measures included pure tone thresholds, tympanometry and acoustic reflexes, word recognition in quiet and in competing message, and the Hearing Handicap Inventory for the Elderly-Screening (HHIE-S) version. Hearing loss in the auditory domains of pure tone thresholds, word recognition in quiet, and word recognition in competing message increased with age but were not significantly different for the veterans and nonveterans. No significant differences were found between participant groups on the HHIE-S; however, regarding hearing aid usage, mixed differences were found.
\end{abstract}

Key words: auditory domains, dizziness, hearing aid, nonveteran, pure tone thresholds, smoking, tinnitus, veteran, word recognition in competing message, word recognition in quiet.

\section{INTRODUCTION}

Hearing loss is one of the most common chronic health conditions among older individuals. Studies indicate the prevalence of hearing loss in the elderly population (>65 years) ranges from 27 to 45 percent and increases with age [1-6]. The results from one population- based study focusing on the prevalence of hearing loss, the Epidemiology of Hearing Loss Study (EHLS) conducted in Beaver Dam, Wisconsin [7], indicated that 46 percent of older adults were affected by hearing loss. The prevalence of hearing loss increased with age and was more common in men than in women. Anecdotally, the percept is that because of noise exposure experienced in the military service, veterans have more hearing loss than do nonveterans. To date, no studies have focused on the prevalence of hearing loss among the veteran population.

The population-based EHLS was an outgrowth of the Beaver Dam Eye Study of age-related eye disorders that enrolled 4,926 participants between 1988 and 1990 [8-9]. Of the 4,541 available participants at the 5-year follow-up

\footnotetext{
Abbreviations: ANOVA $=$ analysis of variance, EHLS $=$ Epidemiology of Hearing Loss Study, HFPTA = high-frequency pure tone average, HHIE-S = Hearing Handicap Inventory for the Elderly-Screening (version), HL = hearing level, LE = left ear, NU-6 $=$ Northwestern University Auditory Test No. 6, PTA = pure tone average, $\mathrm{RE}=$ right ear, $\mathrm{SD}=$ standard deviation, SNR = signal-to-noise ratio, VA = Department of Veterans Affairs.

*Address all correspondence to Richard $\mathrm{H}$. Wilson, PhD; VA Medical Center, Audiology/Research Audiology (126), Mountain Home, TN 37684-4000; 423-979-3561; fax: 423979-3403. Email: richard.wilson2@va.gov

DOI:10.1682/JRRD.2009.10.0169
} 
visit of the Eye Study, 3,753 individuals (82.6\%) agreed to participate in the EHLS between March 1993 and July 1995 [7]. The average age was 65.8 years, and 57.7 percent of the participants were women. Because the EHLS queried the participants about their status as a veteran from one of the U.S. military services, the EHLS provided researchers a unique opportunity to examine characteristics of veterans and nonveterans from the same community. In this context, a veteran refers to anyone who served in any branch of the military services. Of the 3,753 EHLS participants, 1,021 (27.2\%) reported military service with 22 females and 999 males. Because the 22 females were a substantial minority (2.2\%), only the data from 1,589 males (veterans and nonveterans) were analyzed. This article compares and contrasts several general health parameters and the auditory functioning of 590 male nonveterans (37.1\%) and 999 male veterans (62.9\%) in the population. Of the veterans, 70.3 percent served during wartime, most of which were in World War II $(n=396)$, Korea $(n=220)$, and Vietnam $(n=86)$.

The primary purpose of this study was to determine the prevalence of hearing loss among male veterans and nonveterans aged 48 to 92 years who were enrolled in the EHLS. The specific questions were-

1. Is there a higher prevalence of hearing loss for pure tones among veterans compared with nonveterans in the EHLS?

2. Is there a higher prevalence of hearing impairment for word recognition in quiet and in competing message among veterans compared with nonveterans in the EHLS?

3. What is the prevalence of self-assessed hearing handicap among veterans compared with nonveterans?

4. Are veterans more or less likely to use hearing health care services (have their hearing tested, try hearing aids, continue to use hearing aids, etc.) compared with nonveterans?

\section{METHODS}

As detailed by Cruickshanks et al. [7], the auditory examination included a history of ear- and hearing-related issues, otoscopy, screening tympanometry [10-11], airconduction thresholds at 250 to $8,000 \mathrm{~Hz}$ octave intervals and at 3,000 and $6,000 \mathrm{~Hz}$ interoctaves, bone-conduction thresholds at 500 and $4,000 \mathrm{~Hz}$, and word recognition in quiet and in competing message. We examined selfassessed hearing handicap using the Hearing Handicap
Inventory for the Elderly-Screening (HHIE-S) version [12]. Except for 132 homebound residents who were tested in their homes, all other auditory testing was completed in a sound booth. The pure tone audiometry was conducted according to established guidelines [13]. Word-recognition in quiet and in competing message were evaluated on one ear with the Department of Veterans Affairs (VA) female speaker version [14-15] of Northwestern University Auditory Test No. 6 (NU-6) [16]. The ear selected for word recognition was either the ear with better (lower) pure tone thresholds or the right ear (RE) if the pure tone thresholds were equal. In quiet, the word-recognition materials were presented nominally $36 \mathrm{~dB}$ above the $2,000 \mathrm{~Hz}$ threshold in the test ear. In the competing message condition, the sentences spoken by a male were presented $8 \mathrm{~dB}$ below the presentation level of the target words, i.e., at a signal-tonoise ratio (SNR) of $8 \mathrm{~dB}$. Historically, pure tone thresholds are the "gold standard" for expressing hearing loss. In a slightly different viewpoint in this article, pure tone thresholds are considered but one domain of auditory function with other domains, including word recognition in quiet and the word recognition in the competing message. The prevalence of hearing loss in the nonveteran and veteran populations of the Beaver Dam cohort was examined in these three domains of auditory function. The analyses used the chi-square test of association for categorical variables, the Mantel Haenszel chi-square test of trend for ordinal data [17], and $t$-tests of mean differences for continuous data (SAS Institute, Inc; Gary, North Carolina).

\section{RESULTS AND DISCUSSION}

\section{General Demographics}

The demographic data in Table 1 provide information about the 590 nonveterans and 999 veterans included in EHLS. The percentage of nonveterans and veterans in each of the four age groups varied, which is reflected in the significant $\chi^{2}$. With veterans and nonveterans combined in each age group, veterans comprised the majority of the three youngest groups (53.6\% of the 48-59 years group, $79.6 \%$ of the $60-69$ years group, and $66.9 \%$ of the 70 79 years group), whereas the nonveterans comprised the majority of the oldest group (72.8\% of $80-92$ years). The nonveteran and veteran groups also were significantly different in the education category. About 30 percent of both groups were in the two college categories. More nonveterans (32.2\%) than veterans (21.3\%) reported less than a 
high school education, whereas more veterans (46.2\%) than nonveterans (36.6\%) completed high school, which may reflect the often-used requirement of a high school diploma for acceptance into military service. Although the two groups of participants were significantly different in the marriage category, the profiles were strikingly similar with the majority of each group married (nonveterans $78.0 \%$ and veterans $83.9 \%$ ). In the final category in Table 1, the longest held job, which was taken from the 1980 census classifications, the two groups of participants differed significantly, which is probably attributable to two of the categories in which the largest differences were observed, namely, service and farming/forestry. The percentages of nonveterans and veterans in the other four "longest held job" categories were very similar.

Table 2 provides the distributions for four general health categories and two ear-related categories for the two groups of participants. The two groups of participants

Table 1.

Number and percentage of nonveteran male participants and veterans in four demographic categories. Chi-square was used to generate $p$-values.

\begin{tabular}{|c|c|c|c|c|c|}
\hline \multirow{2}{*}{ Category } & \multicolumn{2}{|c|}{ Nonveterans } & \multicolumn{2}{|c|}{ Veterans } & \multirow{2}{*}{$p$-Value } \\
\hline & $n$ & $\%$ & $n$ & $\%$ & \\
\hline Age (yr) & & & & & $<0.001$ \\
\hline $48-59$ & 274 & 46.4 & 317 & 31.7 & - \\
\hline $60-69$ & 102 & 17.3 & 399 & 39.9 & - \\
\hline $70-79$ & 123 & 20.9 & 249 & 24.9 & - \\
\hline 80-92 & 91 & 15.4 & 34 & 3.4 & - \\
\hline Total & 590 & 100.0 & 999 & 100.0 & - \\
\hline Education & & & & & $<0.001$ \\
\hline$<$ High school & 190 & 32.2 & 213 & 21.3 & - \\
\hline High school & 216 & 36.6 & 461 & 46.2 & - \\
\hline Some college & 67 & 11.4 & 144 & 14.4 & - \\
\hline College or greater & 117 & 19.8 & 181 & 18.1 & - \\
\hline Total & 590 & 100.0 & 999 & 100.0 & - \\
\hline Marital Status & & & & & 0.003 \\
\hline Married & 440 & 78.0 & 809 & 83.9 & - \\
\hline Single & 32 & 5.6 & 27 & 2.9 & - \\
\hline Divorced & 37 & 6.6 & 65 & 6.7 & - \\
\hline Widowed & 55 & 9.8 & 63 & 6.5 & - \\
\hline Total & 564 & 100.0 & 964 & 100.0 & - \\
\hline Longest Held Job & & & & & $<0.001$ \\
\hline Manager/Professional & 113 & 19.9 & 206 & 21.1 & - \\
\hline Technician & 71 & 12.5 & 144 & 14.8 & - \\
\hline Service & 47 & 8.3 & 139 & 14.3 & - \\
\hline Farming/Forestry & 78 & 13.7 & 26 & 2.7 & - \\
\hline Production & 149 & 26.2 & 250 & 25.7 & - \\
\hline Operations/Fabricators & 110 & 19.4 & 208 & 21.4 & - \\
\hline Total & 568 & 100.0 & 973 & 100.0 & - \\
\hline
\end{tabular}

were significantly different in the smoking status category, which is mainly attributable to more veterans (59.5\%) with a smoking history than nonveterans (47.9\%). The encouraging statistic is that current smoking is down to about 15 percent in both groups, which demonstrates a substantial decrease in smoking for both groups of participants. The two groups of participants did not differ in the three remaining general health categories in Table 2, diabetes, history of myocardial infarction, and history of head injury. Finally, from Table 2, the two groups of participants did not differ in the rates at which either dizziness or tinnitus had been experienced in the past year. For nonveterans and veterans, respectively, dizziness ranged from 9.9 to 11.8 percent, whereas tinnitus ranged from 7.9 to 9.3 percent.

Finally, handedness was checked by asking, Are you left-handed or right-handed? Handedness was the same for both groups of participants with 89 percent responding right handed, 7 percent responding left handed, and 4 percent responding ambidextrous (data not shown in Table 2).

Table 2.

Number and percentage of nonveteran and veteran male participants in six health categories. Chi-square was used to generate $p$-values.

\begin{tabular}{|c|c|c|c|c|c|}
\hline \multirow{2}{*}{ Category } & \multicolumn{2}{|c|}{ Nonveterans } & \multicolumn{2}{|c|}{ Veterans } & \multirow{2}{*}{$p$-Value } \\
\hline & $n$ & $\%$ & $n$ & $\%$ & \\
\hline Smoking Status & & & & & $<0.001$ \\
\hline Never & 215 & 38.0 & 230 & 23.8 & - \\
\hline Past & 271 & 47.9 & 576 & 59.5 & - \\
\hline Current & 80 & 14.1 & 162 & 16.7 & - \\
\hline Total & 566 & 100.0 & 968 & 100.0 & - \\
\hline Diabetes & & & & & 0.89 \\
\hline Yes & 58 & 10.4 & 101 & 10.6 & - \\
\hline No & 501 & 89.6 & 852 & 89.4 & - \\
\hline Total & 559 & 100.0 & 953 & 100.0 & - \\
\hline History Myocardial Infarction & & & & & 0.08 \\
\hline Yes & 57 & 10.1 & 126 & 13.1 & - \\
\hline No & 508 & 89.9 & 836 & 86.9 & - \\
\hline Total & 565 & 100.0 & 962 & 100.0 & - \\
\hline History Head Injury & & & & & 0.36 \\
\hline Yes & 231 & 39.2 & 368 & 36.8 & - \\
\hline No & 359 & 60.8 & 631 & 63.2 & - \\
\hline Total & 590 & 100.0 & 999 & 100.0 & - \\
\hline Dizziness Past Year & & & & & 0.23 \\
\hline Yes & 58 & 9.9 & 118 & 11.8 & - \\
\hline No & 529 & 90.1 & 880 & 88.2 & - \\
\hline Total & 587 & 100.0 & 998 & 100.0 & - \\
\hline Tinnitus Past Year & & & & & 0.33 \\
\hline Yes & 46 & 7.9 & 93 & 9.3 & - \\
\hline No & 538 & 92.1 & 905 & 90.7 & - \\
\hline Total & 584 & 100.0 & 998 & 100.0 & - \\
\hline
\end{tabular}




\section{Veteran-Specific Demographics}

Table 3 describes certain service-related characteristics of the 999 veterans involved in the study. (Note: Because of missing or incomplete data for a variety of reasons, the number of participants varies slightly throughout the tables in the manuscript.) Most were in the Army (60.0\%), equal numbers in the Navy and Air Force (16\%-17\%), and fewer were in the Marines (5.2\%) and Coast Guard (0.9\%). Most of the veterans were in the service 5 years or fewer, with 35.3 percent in for 1 to 2 years and 40.2 percent in for 3 to 5 years. The primary service occupation was support (72.1\%), with frontline combat $(18.3 \%)$ and combat support (9.6\%) minority occupations.

\section{Leisure Time Noise Exposure}

We included the categories in Table 4 to determine the extent to which the participants in EHLS were exposed to noise in their civilian lives. The distributions of the responses to the three categories of "noisy environments" were almost identical, with the differences between groups not significant at the 0.01 level. For example, 34.2 percent

Table 3.

Number and percentage of male veterans in respective branches of armed services and years of military service.

\begin{tabular}{lrr}
\hline \multicolumn{1}{c}{ Category } & $\boldsymbol{n}$ & \% \\
\hline Branch of Service & 608 & 60.0 \\
Army & 176 & 17.4 \\
Navy & 167 & 16.5 \\
Air Force & 53 & 5.2 \\
Marines & 9 & 0.9 \\
Coast Guard & $1,013^{*}$ & 100.0 \\
Total & & \\
Service Years & 353 & 35.3 \\
1-2 & 402 & 40.2 \\
3-5 & 158 & 15.8 \\
6-9 & 31 & 3.2 \\
10-19 & 55 & 5.5 \\
20+ & 999 & 100.0 \\
Total & & \\
Primary Service Activity & 182 & 18.3 \\
Front Line & 95 & 9.6 \\
Combat Support & 718 & 100.0 \\
Other Support & 995 & \\
Total & & \\
*Some participants were in more than one service. & \\
& & \\
\hline
\end{tabular}

Table 4.

Number and percentage of male nonveterans and veterans who reported participating in three activities that are considered noisy. Chisquare was used to generate $p$-values.

\begin{tabular}{|c|c|c|c|c|c|}
\hline \multirow{2}{*}{ Category } & \multicolumn{2}{|c|}{ Nonveterans } & \multicolumn{2}{|c|}{ Veterans } & \multirow{2}{*}{$p$-Value } \\
\hline & $n$ & $\%$ & $n$ & $\%$ & \\
\hline Woodworking & & & & & 0.09 \\
\hline Yes & 202 & 34.2 & 385 & 38.5 & 一 \\
\hline No & 388 & 65.8 & 614 & 61.5 & - \\
\hline Total & 590 & 100.0 & 999 & 100.0 & - \\
\hline Hunting/Fired Gun & & & & & 0.98 \\
\hline Yes & 442 & 74.9 & 749 & 75.0 & - \\
\hline No & 148 & 25.1 & 250 & 25.0 & - \\
\hline Total & 590 & 100.0 & 999 & 100.0 & 一 \\
\hline Target Shooting & & & & & 0.01 \\
\hline Yes & 75 & 12.7 & 173 & 17.3 & - \\
\hline No & 515 & 87.3 & 826 & 82.7 & - \\
\hline Total & 590 & 100.0 & 999 & 100.0 & - \\
\hline
\end{tabular}

of the nonveterans and 38.5 percent of the veterans reported involvement in woodworking. The numbers for hunting were even closer, 74.9 versus 75.0 percent. Only target shooting approached a level of significance with participation by 12.7 and 17.3 percent of the nonveterans and veterans, respectively. The data in Table 4 suggest that no difference exists between veterans and nonveterans in their participation in noisy leisure activities.

\section{Pure Tone Thresholds}

Of the 1,589 males between 48 and 92 years of age who were enrolled in the study, 49 participants were able to complete only the interview portion of the protocol and not the objective measures, such as, pure tone thresholds. Additionally, two participants were evaluated in a nursing home but were unable to complete the objective testing. Thus the objective pure tone and speech-recognition data reported in the following paragraphs are from 568 nonveterans (mean age 64.6 years \pm 11.8 standard deviation [SD]) and 970 veterans (64.6 \pm 8.6 years). Various combinations of the mean left-ear (LE) and RE audiograms for the nonveteran and veteran groups of EHLS participants are shown in Figure 1 (all ages by subgroup) and in Figure 2 (four age groups by participant group).

Figure 1(a) depicts the mean nonveteran and veteran LE audiograms and Figure 1(b) RE audiograms, whereas Figure 1(c) shows the mean RE and LE audiograms for the nonveterans (filled circles and squares) and Figure 1(d) veterans (open circles and times symbols). The mean 

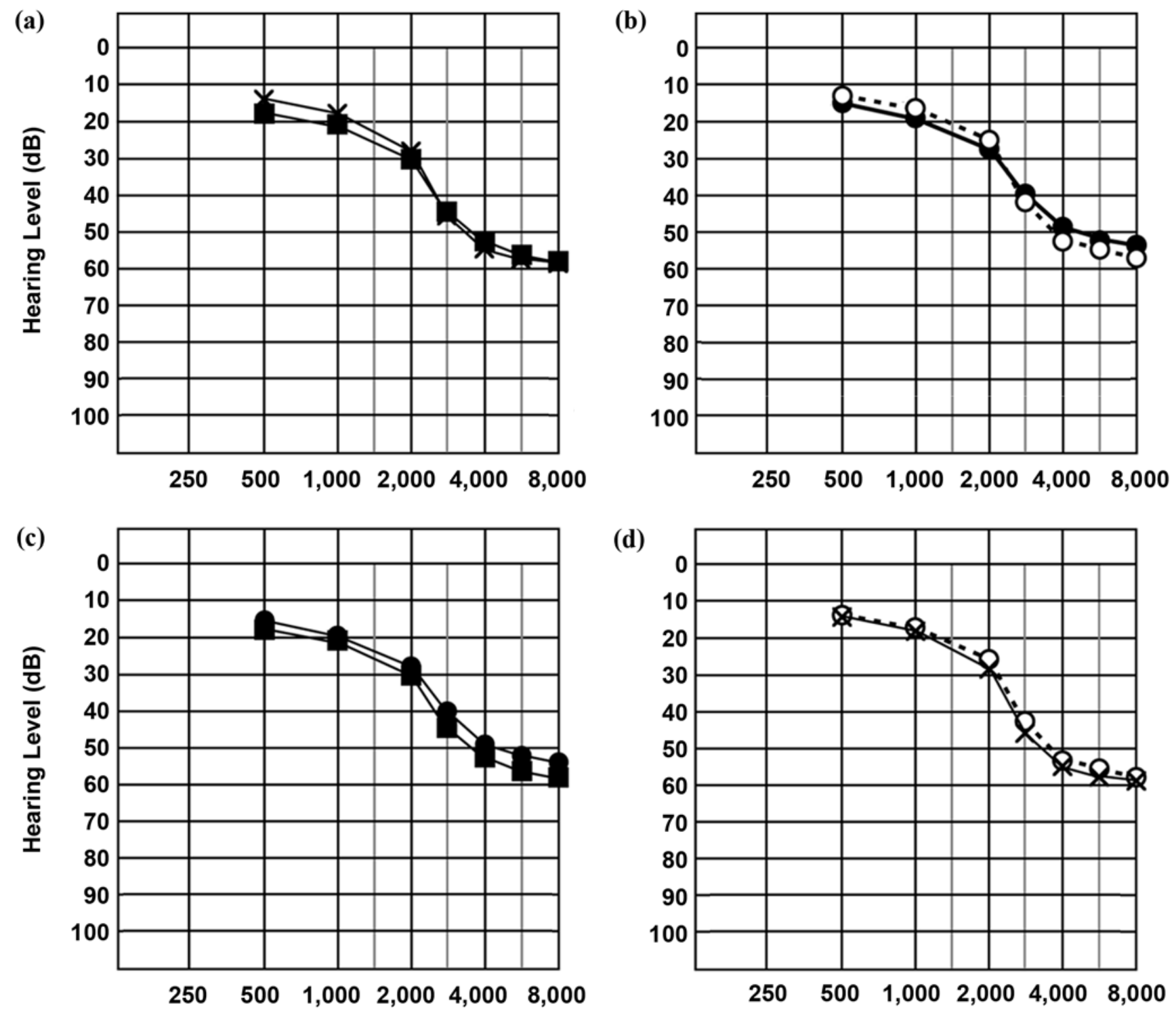

Frequency $(\mathrm{Hz})$

Figure 1.

Mean audiograms for male nonveterans and veterans in Epidemiology of Hearing Loss Study. Data depict mean audiograms grouped by (a) left ear (LE), (b) right ear (RE) nonveterans ([filled symbols] and veterans [times and open symbols]), (c) nonveterans, and (d) veterans (LE [squares and times symbols] and RE [circles]). Source: Specifications for audiometers. ANSI S3.6-1989. New York (NY): American National Standards Institute; 1989.

audiograms indicate normal hearing at 500 and $1,000 \mathrm{~Hz}$ for both ears of each participant group. From 2,000 to 8,000 Hz, the audiograms reflect mild to moderate hearing loss with 25 to $30 \mathrm{~dB}$ hearing level (HL) [18] thresholds at 2,000 Hz progressing to 55 to $60 \mathrm{~dB}$ HL thresholds at $8,000 \mathrm{~Hz}$. For both ears, the veterans had slightly better hearing in the lower frequencies by 2 to $4 \mathrm{~dB}$ than did the nonveterans.
Conversely, in the higher frequencies, the nonveterans had slightly better hearing by 2 to $3 \mathrm{~dB}$ than did the veterans. Similarly as shown in Figure 1(c) and (d), the between-ear pure tone threshold differences for both groups of participants were small, ranging from $0.2 \mathrm{~dB}$ at $500 \mathrm{~Hz}$ to $3.3 \mathrm{~dB}$ at $3,000 \mathrm{~Hz}$ for the veteran group and from $1.1 \mathrm{~dB}$ at $1,000 \mathrm{~Hz}$ to $4.8 \mathrm{~dB}$ at $3,000 \mathrm{~Hz}$ for the nonveteran group. 
Interestingly, all the mean pure tone thresholds for the LE were at higher (poorer) levels than were the mean thresholds for the RE, which is an effect described in a subsequent paragraph.

The mean pure tone thresholds are presented in Figure 2 for each of four age categories (48-59, 60-69, 70-79, and $80+$ years) for the nonveteran and veteran groups. Because of the minimal differences between the $\mathrm{RE}$ and LE mean audiograms, only the mean thresholds for the RE are shown. As a point of reference, the light line in the graphs for the three older groups represents a composite of the thresholds for the youngest group of participants. Except for the 80+ years group, the mean thresholds for the veterans and nonveterans are within a (a)

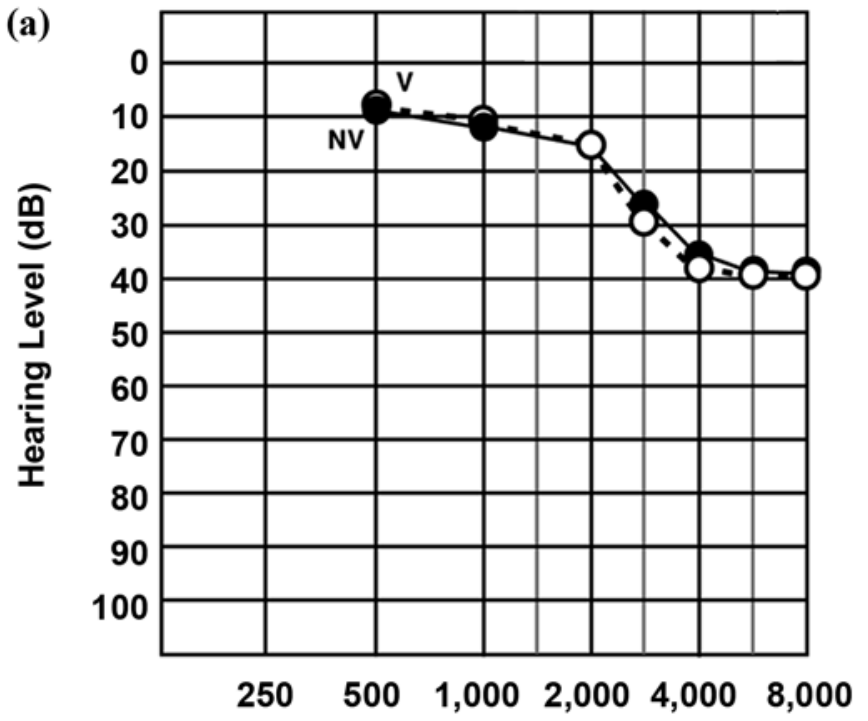

(c)

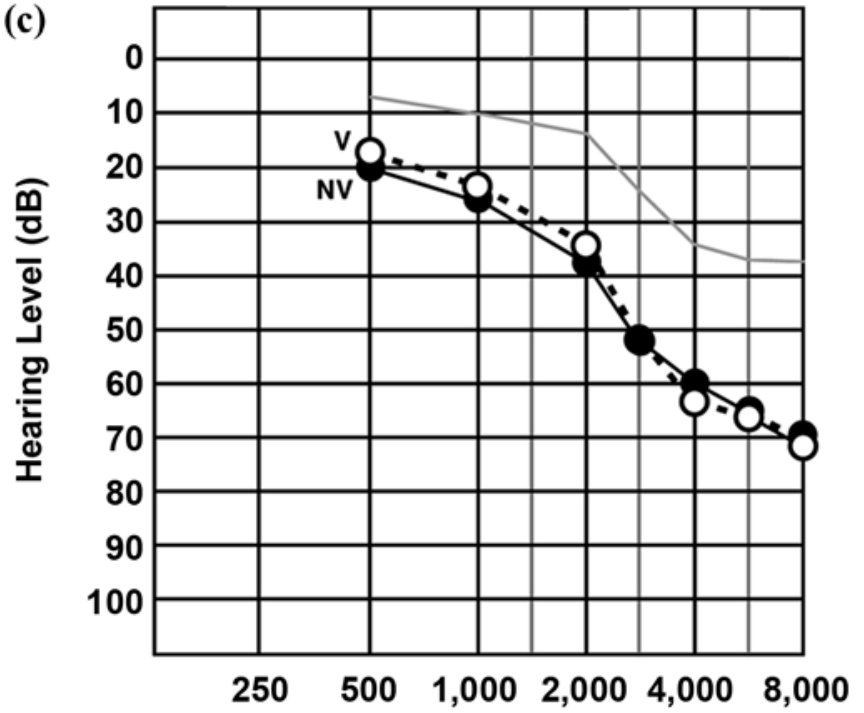

(b)

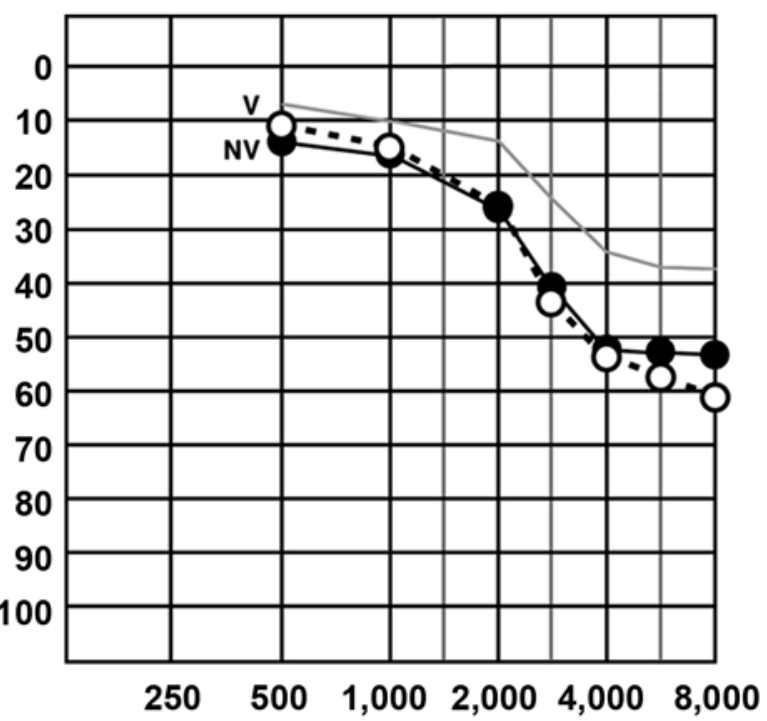

(d)

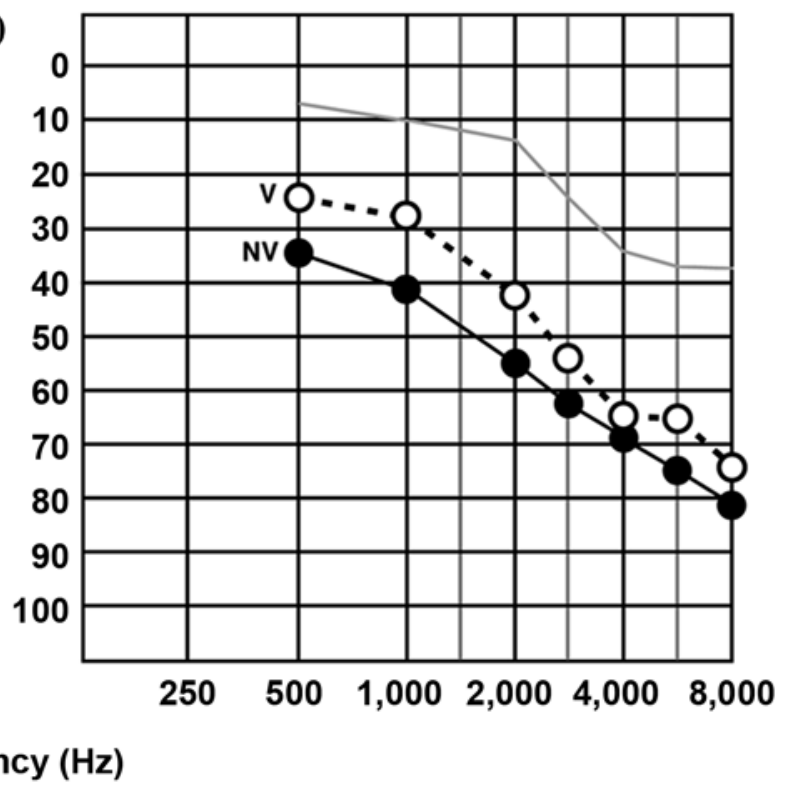

Figure 2.

Mean audiograms for right ears of male veterans (V) (open circles) and nonveterans (NV) (filled symbols) in four age-group categories: (a) 48-59 yr, (b) 60-69 yr, (c) 70-79 yr, and (d) 80+ yr. Light line in graphs for oldest three groups is threshold function from 48-59 yr group. Source: Specifications for audiometers. ANSI S3.6-1989. New York (NY): American National Standards Institute; 1989. 
few decibels of one another. Although the veterans in the $80+$ years group had 5 to $10 \mathrm{~dB}$ lower (better) thresholds than the nonveterans, these findings must be viewed with caution because of the small number of participants who comprise the two groups in the oldest age range, which in this comparison were 83 nonveterans and only 34 veterans.

To evaluate the significance of the observations seen in Figures 1 and 2, we used $t$-tests to examine thresholds. An initial paired-samples $t$-test was used for looking at thresholds collapsed across frequency, age, and veteran status for the RE and LE. The resulting statistic $(t(1,504)=$ $-7.04, p<0.001)$ was significant, confirming that on average, thresholds were lower (better) for the RE than the LE. The average difference between ears is assumed for both veterans and nonveterans because additional $t$-test results showed no significant differences for either ear as a function of veteran status. Thresholds as a function of frequency and age were other variables of interest. Two metrics commonly used to define hearing loss in terms of pure tone thresholds are the traditional pure tone average (PTA) of thresholds at 500, 1,000, and 2,000 Hz and the high-frequency PTA (HFPTA) of thresholds at 1,000, 2,000 , and $4,000 \mathrm{~Hz}$ [19]. A one-way analysis of variance (ANOVA) across the four age categories showed that PTA increased significantly with each increment in age group $\left(F_{w}(3,438)=141.7, p<0.001\right)$. Similarly, for the HFPTA, we observed that each increment in age group $\left(F_{w}(3,456)=\right.$ 199.8, $p<0.001$ ) increased significantly.

To this point, the data indicate that the hearing sensitivity of the veterans and nonveterans among the age groups and collectively is strikingly similar. The PTAs for the veterans and nonveterans are listed in Table 5 for the four age groups. The only significant PTA difference between groups was with the $80+$ year olds $(t(93)=-3.3$, $p=0.001)$. The mean PTAs for the 48- to 59-years and the 60- to 69-years groups were well within the normal range of $\leq 20 \mathrm{~dB} \mathrm{HL}$, with the means for the 70 - to 79-years groups only outside the normal range by 3 to $5 \mathrm{~dB}$. The $80+$ years groups were outside the normal range for PTAs by $10 \mathrm{~dB}$ (veterans) and by $\leq 20 \mathrm{~dB}$ (nonveterans), but again, the disparity in the number of participants in each group probably influenced the outcome.

Table 5.

Mean three-frequency pure tone average (PTA) at 500, 1,000, and 2,000 Hz; mean high-frequency PTA (HFPTA) at 1,000, 2,000, and 4,000 Hz; and mean word-recognition scores on Northwestern University Auditory Test No. 6 materials in quiet (Q) and in competing message (CM) for ear tested for word recognition for male nonveterans (NV) and veterans (V).

\begin{tabular}{|c|c|c|c|c|c|c|c|c|}
\hline \multirow[t]{2}{*}{ Age/Statistic } & \multicolumn{2}{|c|}{$\begin{array}{c}\text { PTA }(0.5,1,2) \\
\text { (dB HL) }\end{array}$} & \multicolumn{2}{|c|}{$\begin{array}{l}\text { HFPTA }(1,2,4) \\
\text { (dB HL) }\end{array}$} & \multicolumn{2}{|c|}{$\begin{array}{l}\text { Words (Q) } \\
\text { (\% Correct) }\end{array}$} & \multicolumn{2}{|c|}{$\begin{array}{l}\text { Words (CM) } \\
\text { (\% Correct) }\end{array}$} \\
\hline & NV & $\mathbf{V}$ & NV & V & NV & V & NV & $\mathbf{V}$ \\
\hline \multicolumn{9}{|l|}{$\overline{48-59 \text { Years }}$} \\
\hline Mean & 10.0 & 11.5 & 19.1 & 21.9 & 90.7 & 90.7 & 58.5 & 56.3 \\
\hline SD & 8.2 & 12.2 & 11.1 & 17.4 & 6.9 & 6.3 & 16.6 & 16.0 \\
\hline$n$ & 265 & 307 & 265 & 307 & 257 & 297 & 252 & 302 \\
\hline \multicolumn{9}{|l|}{ 60-69 Years } \\
\hline Mean & 15.5 & 15.6 & 27.5 & 29.7 & 87.4 & 87.3 & 47.0 & 45.7 \\
\hline SD & 12.1 & 10.7 & 14.7 & 13.8 & 11.9 & 10.5 & 19.7 & 18.6 \\
\hline$n$ & 99 & 391 & 99 & 390 & 95 & 370 & 96 & 371 \\
\hline \multicolumn{9}{|l|}{ 70-79 Years } \\
\hline Mean & 25.2 & 23.0 & 38.8 & 37.3 & 81.0 & 82.0 & 33.9 & 32.8 \\
\hline SD & 15.4 & 13.2 & 15.8 & 14.5 & 15.4 & 15.6 & 19.2 & 19.6 \\
\hline$n$ & 121 & 237 & 120 & 236 & 114 & 223 & 108 & 217 \\
\hline \multicolumn{9}{|l|}{ 80+ Years } \\
\hline Mean & 39.0 & 29.5 & 53.2 & 43.5 & 63.9 & 78.2 & 15.2 & 24.9 \\
\hline SD & 18.4 & 12.2 & 15.7 & 12.5 & 20.7 & 11.7 & 16.7 & 17.3 \\
\hline$n$ & 81 & 34 & 81 & 34 & 73 & 32 & 60 & 23 \\
\hline \multicolumn{9}{|l|}{ Grand Mean } \\
\hline Mean & 18.4 & 16.0 & 29.6 & 29.0 & 84.4 & 86.8 & 46.2 & 46.2 \\
\hline SD & 16.1 & 12.1 & 18.3 & 15.0 & 15.3 & 11.6 & 23.1 & 19.9 \\
\hline$n$ & 566 & 969 & 565 & 967 & 539 & 922 & 516 & 913 \\
\hline
\end{tabular}


Several investigators have suggested that the ability to understand speech (especially in background noise) is in part related to auditory function in the frequencies above 2,000 Hz [20-21]. Accordingly, the HFPTAs were also derived for each participant group and are listed in Table 5. As with the PTA, only the $80+$ years groups mean HFPTAs were significantly different $(t(85)=-3.2$, $p=0.002)$. Not surprisingly, all the differences between the PTA and the HFPTA were significant at 0.01. The mean HFPTAs for the 48- to 59-years groups are about $10 \mathrm{~dB}$ poorer (higher) than the traditional PTA, but the HFPTAs continue in the normal $\leq 20 \mathrm{~dB}$ HL range. For the three remaining age groups, the differences between the mean PTAs and the mean HFPTAs are larger with the HFPTAs 12 to $14 \mathrm{~dB}$ poorer than the traditional PTAs. For the oldest three groups, the mean HFPTAs are progressively poorer than the normal $\leq 20 \mathrm{~dB} H \mathrm{HL}$ range.

The distributions of hearing losses defined with the HFPTA for the four age groups are shown in Figure 3 (veterans) and Figure 4 (nonveterans). The percentage of the participants in the respective groups is on the ordinates with the HFPTA in $10 \mathrm{~dB}$ ranges shown on the abscissas. The bars with diagonal lines represent the LE data, and the shaded bars represent the RE data. The vertical dashed line delimits normal hearing ( $\leq 20 \mathrm{~dB} \mathrm{HL})$ and hearing loss ( $>20 \mathrm{~dB}$ HL), with the numbers in the upper right corner of each graph indicating the percentage of each ear that is to the right of the dashed line, which indicates hearing loss. In the 48- to 59-years groups, 45 to 58 percent of the participants had hearing loss by the $>20 \mathrm{~dB}$ HL criterion, a percentage that increased progressively to 92 to 100 percent of the $80+$ years groups. Defined in this manner, the prevalence of hearing loss is substantial in each age group, systematically increases with increasing age, and is similarly distributed for the veterans and nonveterans. The HFPTA data also can be used by the reader to define the prevalence of hearing loss in the veteran and nonveteran groups using any combination of the hearingloss ranges expressed on the abscissas in Figures $\mathbf{3}$ and $\mathbf{4}$.

\section{Word Recognition in Quiet and in Competing Message}

The mean word-recognition performances in quiet on the NU-6 materials were 86.5 percent $(\mathrm{SD}=11.5 \%$ ) by 904 veterans and 84.0 percent $(S D=15.3 \%)$ by 526 nonveterans. An independent $t$-test showed that the $\sim 2$ percent difference between groups was statistically significant $(t(870)=3.3, p=0.001)$. Although the difference is statistically significant, 2 percent is a one-word difference and (a)

(b)

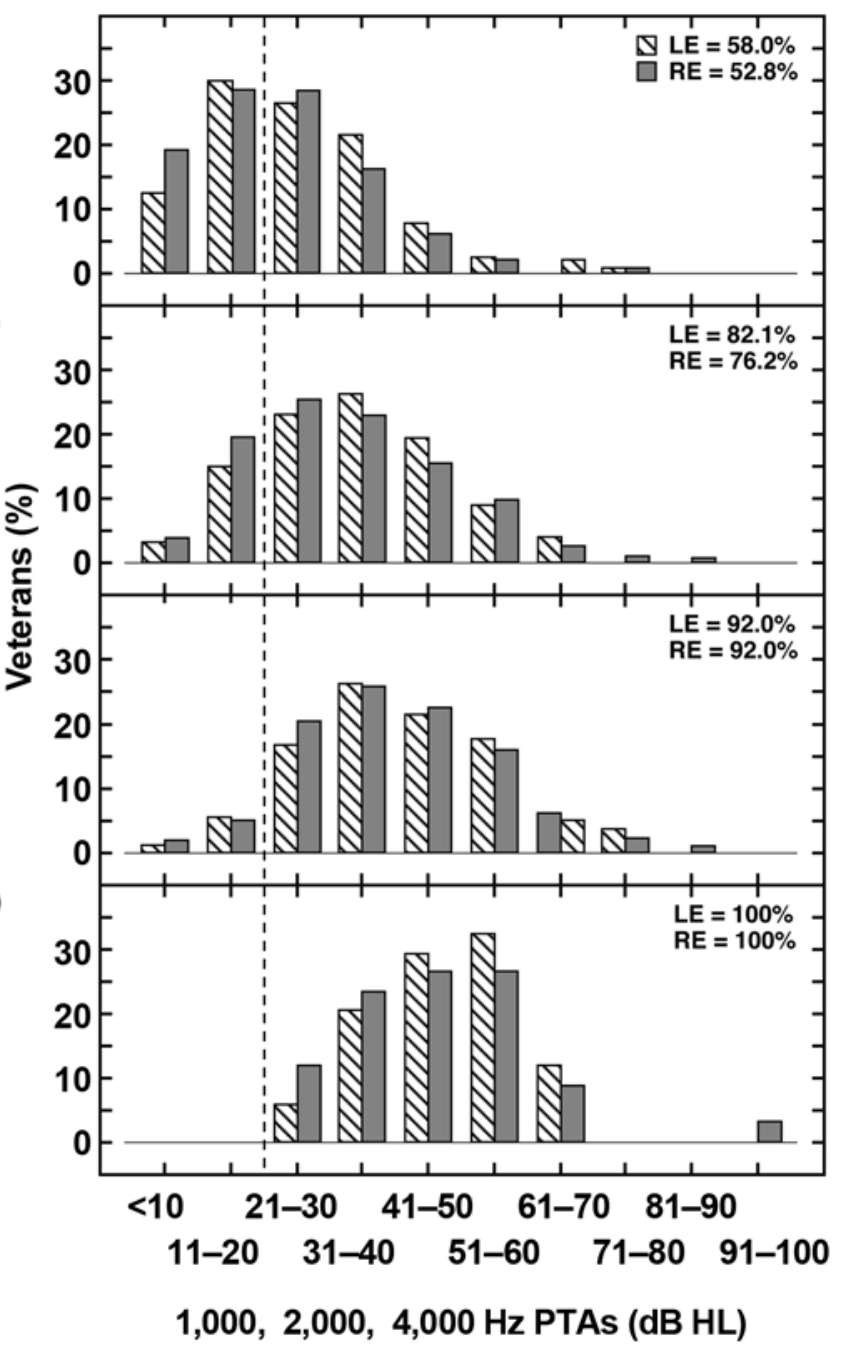

Figure 3.

Histograms depicting percentage of male veteran group with 1,000, 2,000, and 4,000 $\mathrm{Hz}$ pure tone averages (PTAs) within bin ranges indicated on abscissa in each of four age groups: (a) 48-59 yr, (b) 6069 yr, (c) 70-79 yr, and (d) 80+ yr. Data for left ear (LE) (diagonal lines) and right ear (RE) (shaded) are shown. Vertical dashed line delimits normal hearing and hearing-loss categories, with percentages in each upper-right graph, indicating percentage of sample with hearing loss. $\mathrm{HL}=$ hearing level.

is not clinically important. The individual recognition performances in quiet are plotted in Figure $\mathbf{5}$ as a function of the HFPTA of the test ear for the nonveterans (Figure 5(a)) and veterans (Figure 5(b)). The large filled symbol in each graph depicts the mean data, and the line is the linear regression used to describe the data. For both participant groups, the distributions are similar, as reflected by the slopes of the regressions, -0.6 percent $/ \mathrm{dB}$ 
(a)

(b)

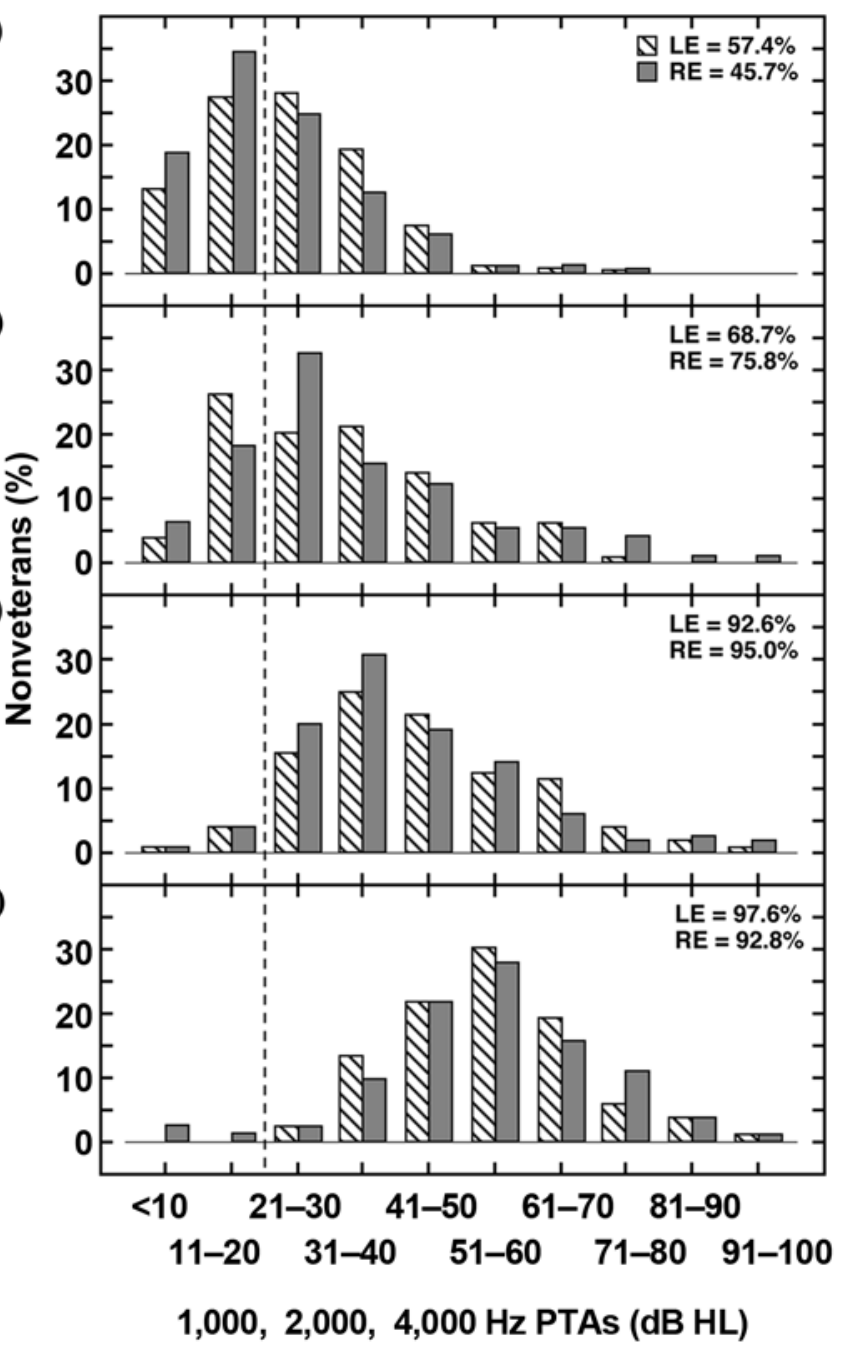

Figure 4.

Histograms depicting percentage of male nonveteran group with 1,000, 2,000, and 4,000 $\mathrm{Hz}$ pure tone averages (PTAs) within bin ranges indicated on abscissa in each of four age groups: (a) 48-59 yr, (b) 60-69 yr, (c) 70-79 yr, and (d) 80+ yr. Data for left ear (LE) (diagonal lines) and right ear (RE) (shaded) are shown. Vertical dashed line delimits normal hearing and hearing-loss categories, with percentages in each upper-right graph, indicating percentage of sample with hearing loss. $\mathrm{HL}=$ hearing level.

and -0.4 percent/dB for nonveterans and veterans, respectively. The mean recognition performances (and SDs) by the nonveterans and veterans in the four age groups on the NU-6 materials in quiet are listed in Table 5. Except for the $80+$ years groups, the mean performances are almost identical for the two groups of participants and are in the range of normal hearing, which is defined as 80 percent correct. Histograms indicating the percentage of the par- (a)

(b)

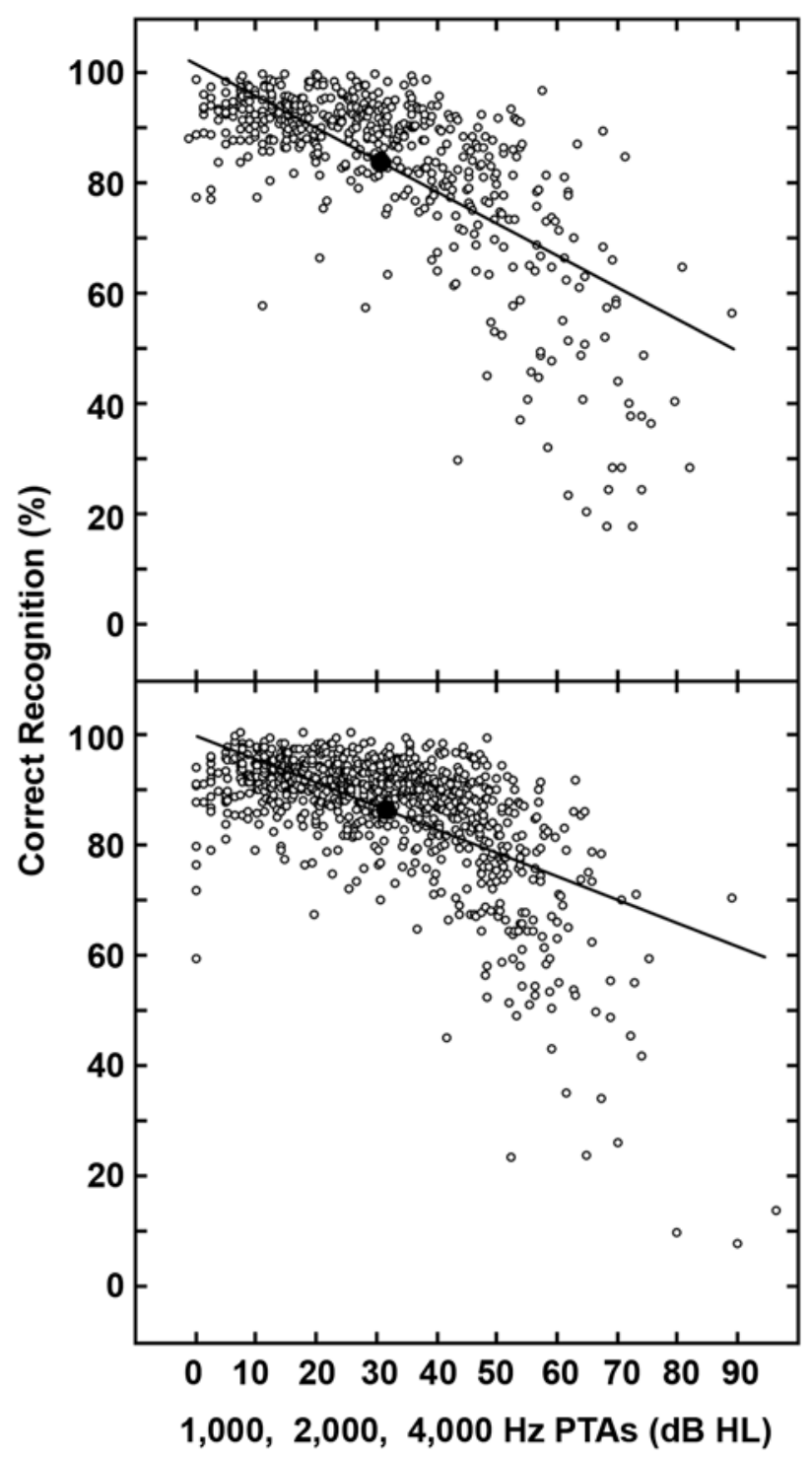

Figure 5.

Bivariate plots of individual word-recognition performances in quiet (ordinate) and high-frequency pure tone average (PTA) of listeners (abscissa) for (a) 526 nonveterans and (b) 904 veterans. Large filled symbols depict mean datum points, and lines through datum points are linear regressions used to describe data $\left(R^{2}=0.48\right.$, nonveterans; $R^{2}=0.36$, veterans). $\mathrm{HL}=$ hearing level.

ticipants in each group (veterans [V], diagonal lines; nonveterans $[\mathrm{NV}]$, shaded) with word-recognition scores in the decade intervals from $<10$ to 100 percent are shown in Figure 6 for the four age groups. The vertical dashed line indicates the boundary between 80 to 100 percent performance (i.e., normal hearing for words in quiet) and 0 to 78 percent performance (i.e., hearing loss for words in quiet). 


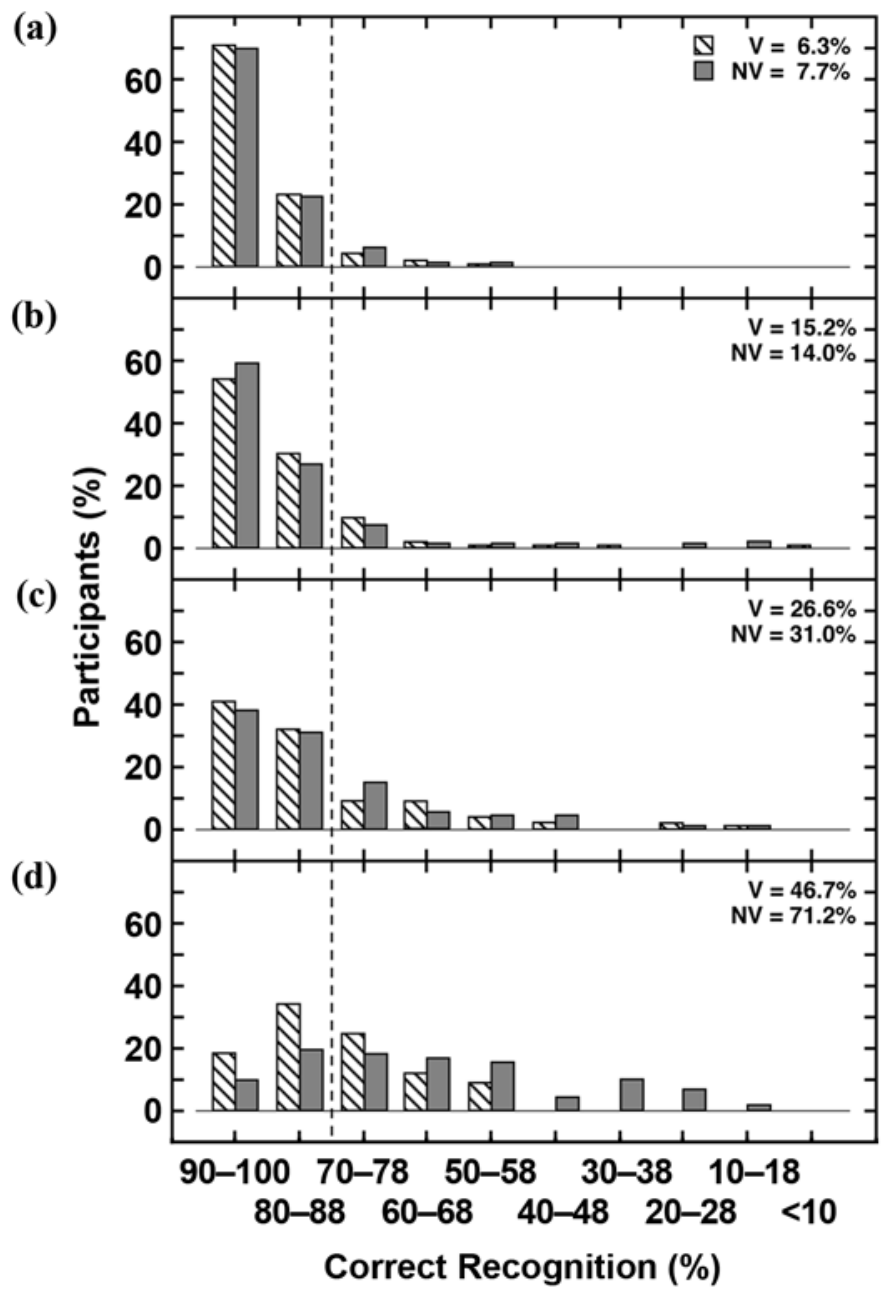

Figure 6.

Histograms showing percentage of male participants in veteran (V) (diagonal lines) and nonveteran (NV) (shaded) groups who obtained word-recognition performance on Northwestern University Auditory Test No. 6 materials presented in quiet within bin ranges indicated on abscissa in each of four age groups: (a) 48-59 yr, (b) 60-69 yr, (c) 70$79 \mathrm{yr}$, and (d) $80+$ yr. Vertical dashed line delimits normal hearing ( $\geq 80 \%$ correct) and hearing-loss ( $\leq 78 \%$ correct) categories, with percentages in each upper-right graph indicating percentage of each group classified with hearing loss in this domain of auditory function.

The percentages in the upper right corner of each graph list the percentage of the participants with hearing loss in this domain of auditory function. Using 80 percent correct recognition as the boundary between performances by listeners with normal hearing and listeners with hearing loss, we found that, as shown in the data in Figures $\mathbf{5}$ and $\mathbf{6}$, the majority of participants had normal auditory functioning in terms of understanding speech in quiet. Even if the boundary were changed to 90 percent correct recognition, the outcome would not be appreciably affected. Finally, when examining performance in quiet by age groups, collapsed across participant groups, we found that a oneway ANOVA differed significantly between each age group, again with performance declining with increasing age $\left(F_{w}(3,372)=77.8, p<0.001\right)$.

The mean word-recognition performances on the NU6 materials in the competing message at $8 \mathrm{~dB}$ SNR were 46.2 percent $(\mathrm{SD}=19.9 \%$ ) by 913 veterans and 46.2 percent $(\mathrm{SD}=23.1 \%)$ by 516 nonveterans. The individual recognition performances in the competing message are plotted in Figure 7 as a function of the HFPTA of the test ear for the nonveterans (Figure $\mathbf{7 ( a ) )}$ and veterans (Figure 7(b)). Again, the data distributions for the participant groups are similar, which is reflected by the comparable regression slopes of -0.98 percent/ $\mathrm{dB}$ and -0.95 percent/ $\mathrm{dB}$ for the nonveterans and veterans, respectively. The mean recognition performances (and SDs) by the nonveterans and veterans in the four age groups on the NU-6 materials in the competing message are listed in Table 5. Except for the $80+$ years groups, the mean performances were within $\sim 2$ percent for the two groups of participants. By defining the range of normal performance on this paradigm as 70 to 100 percent correct, we found that all the mean data were outside the normal range.

Noteworthy is the decrement in performance accelerates across the age groups from an 11 percent difference between the youngest age groups to a 15 percent difference between the oldest age groups. The interval histograms in Figure 8 depict the distribution of recognition performances for the four age groups on the words in the competing message paradigm. Again, the dashed vertical line delimits the boundary between performances by listeners with normal hearing ( $\geq 70 \%$ correct) and listeners with hearing loss ( $<70 \%$ correct). The data in Figure 8 have several points of interest. First, except for the $80+$ years groups, the distributions at the respective age categories are remarkably similar for the two groups of participants, reflecting a broad range of performances. The exception in the $80+$ years groups probably is attributable

\footnotetext{
*Normal performance on NU-6 materials presented in a competing message paradigm [14] was established from Wilson et al. [15] data for same materials presented at $8 \mathrm{~dB}$ SNR. The mean \pm SD for listeners with normal hearing in the Wilson et al. study was $84.5 \%$ correct \pm $5.0 \%$. Based on these data, $\geq 70 \%$ correct was established as the range of normal performance, which is a conservative boundary about 3 SDs from the mean.
} 
(a)

(b)

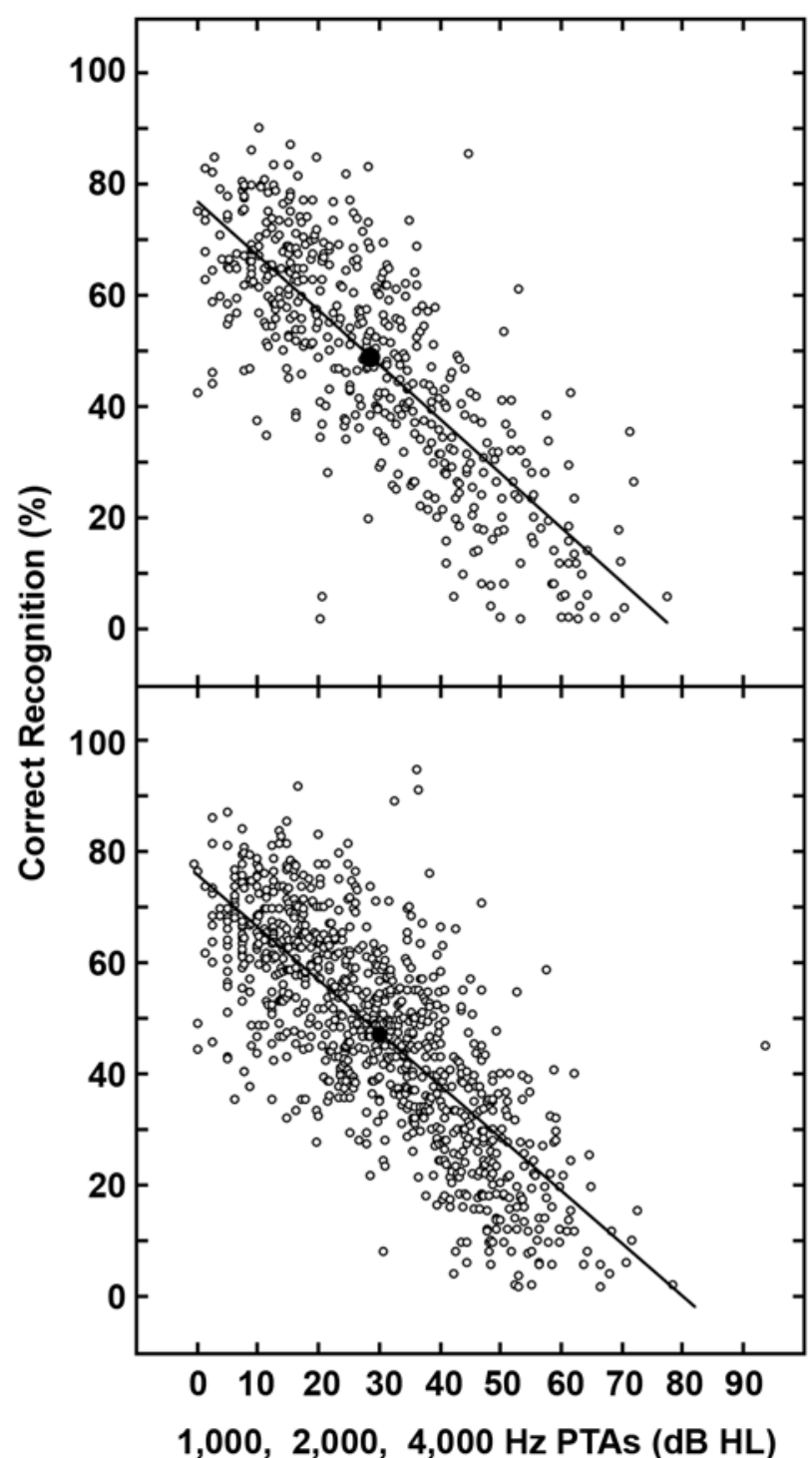

Figure 7.

Bivariate plots of individual word-recognition performances in competing message (ordinate) and high-frequency pure tone averages (PTAs) of listeners (abscissa) for (a) 486 nonveterans and (b) 897 veterans. Large filled symbols depict mean datum points, and lines through datum points are linear regressions used to describe data $\left(R^{2}=\right.$ 0.61 , nonveterans; $R^{2}=0.58$, veterans). $\mathrm{HL}=$ hearing level.

to the small number of participants in the groups, especially the veterans $(n=23)$. Second, across the four age groups, the distributions change with a migration from the left (good performance) to the right (poor performance). Third, the percentages in the upper right of each graph indicate the percentages of participants whose performances fell to the right of the vertical dashed line ( $\geq 70 \%)$. (a)

(b)

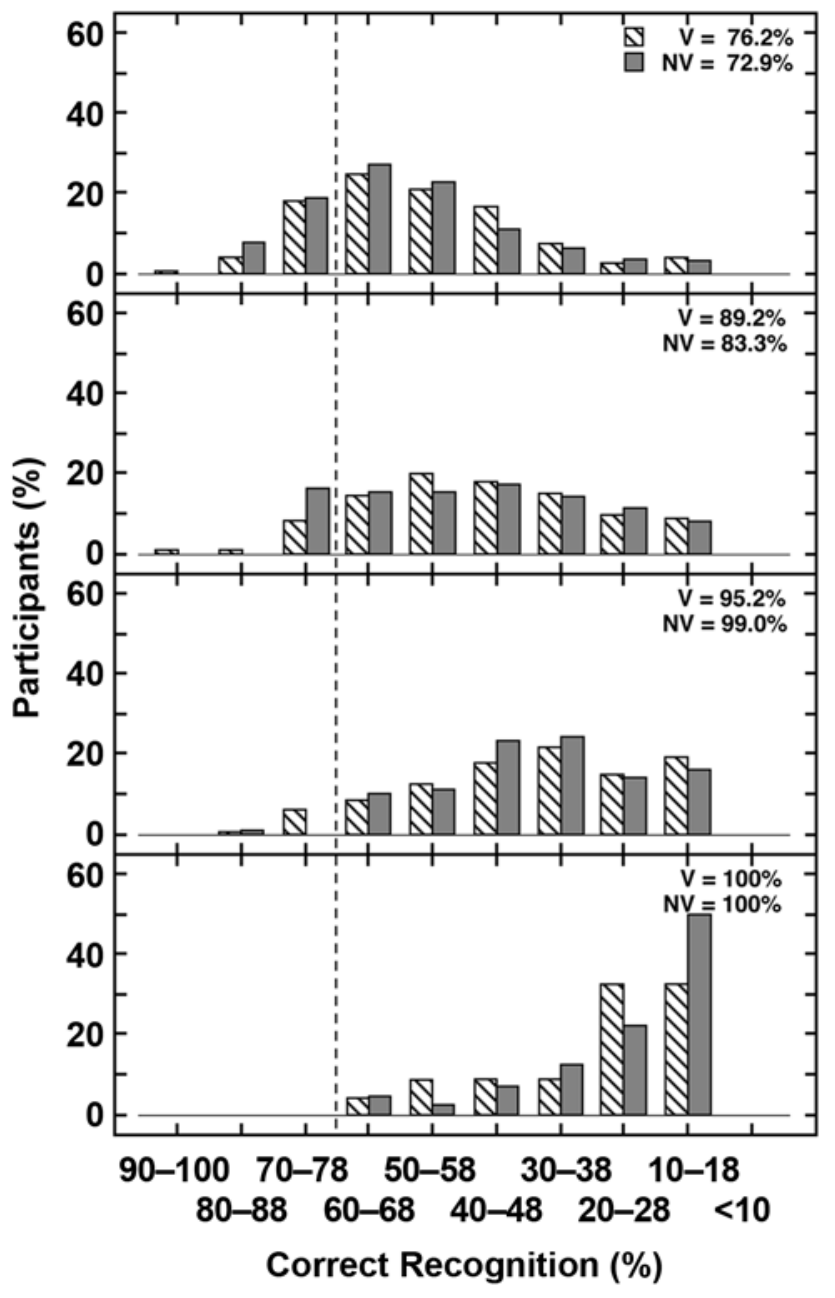

Figure 8.

Histograms showing percentage of male participants in veteran (V) (diagonal lines) and nonveteran (NV) (shaded) groups who obtained word-recognition performance on Northwestern University Auditory Test No. 6 materials presented in competing message at $8 \mathrm{~dB}$ SNR within bin ranges indicated on abscissa in each of four age groups: (a) 48-59 yr, (b) 60-69 yr, (c) 70-79 yr, and (d) 80+ yr. Vertical dashed line delimits normal hearing ( $\geq 70 \%$ correct) and hearing-loss ( $\leq 68 \%$ correct) categories, with percentages in each upper-right graph indicating percentage of each group classified with hearing loss in this domain of auditory function.

The vast majority of participants in each age group (i.e., 72.9\%-100.0\%) had hearing loss for words presented in a competing message or background noise. As with the word-recognition data in quiet, when examining performance in the competing message paradigm by age groups, collapsed across participant groups, we found that a oneway ANOVA differed significantly between each age group, with performance declining with increasing age $\left(F_{w}(3,348)=192.8, p<0.001\right)$. 


\section{HHIE-S}

The auditory data just reported were objective data that quantified a specific domain of auditory function. Self-report instruments also have been used to understand the prevalence of hearing loss or hearing handicap. The HHIE-S [12] was included in the EHLS as a measure of the self-perceived hearing handicap [22], with scores $>8$ indicating a self-reported hearing handicap [23-24] with scores in the 10 to 24 range considered mild to moderate hearing handicap and scores in the 26 to 40 range considered severe handicap [25]. The data in Table 6 list the number (and corresponding percents) of nonveteran and veteran participants by age category. The $p$-values in Table 6 indicate that no differences were found between nonveterans and veterans on the HHIE-S in any of the age groups. Collectively in each age group, most participants scored 8, with about 82, 75, 73, and 64 percent of the 48 to 59, 60 to 69,70 to 79 , and $80+$ years groups, respectively, indicating no self-perceived hearing problem. At the other extreme of the HHIE-S scoring range (26-40), 3, 4, 6, and 11 percent of the participants in the respective age groups suggested severe hearing handicap. The remaining 15 to 25 percent of each age group scored 10 to 24, which indicates a mild to moderate hearing handicap. The HHIE-S data for veterans (diagonal lines) and nonveterans (shaded) by the four age groups are displayed in more discrete intervals in Figure 9 that emphasize the skewness of the distributions toward the lower scores on the HHIE-S. To compare the EHLS of the HHIE-S data with the objective measures of auditory function, the reader is referred to Wiley et al. [22].

\section{Hearing Aid Use}

Finally, EHLS determined two aspects of hearing aid usage from the participants: (1) Had they ever worn a hearing aid? and (2) Were they currently wearing a hearing aid? The hearing aid use data for the nonveteran and veteran groups are listed in Table 7 for the four age categories. Overall, 16 percent of the nonveterans and 11 percent of the veterans had a history of hearing aid use, which was significantly different at 0.01 . Current hearing aid use was less for both groups, 10 percent for the nonveterans and 7 percent for the veterans. This 3 percent between-group difference was significant. For the various age categories, however, no significant differences were found between the nonveterans and veterans regarding hearing aid use. Both the pure tone threshold data and the word-recognition data indicated in general higher thresholds (poorer hear-
Table 6.

Number and percentage of male nonveterans and veterans by age group and overall on various classification categories of Hearing Handicap Inventory for the Elderly-Screening (HHIE-S) version. Chisquare was used to generate $p$-values.

\begin{tabular}{|c|c|c|c|c|c|}
\hline \multirow{2}{*}{$\begin{array}{c}\text { Age/HHIE-S } \\
\text { Category }\end{array}$} & \multicolumn{2}{|c|}{ Nonveterans } & \multicolumn{2}{|c|}{ Veterans } & \multirow{2}{*}{$p$-Value } \\
\hline & $n$ & $\%$ & $n$ & $\%$ & \\
\hline 48-59 Years & & & & & 0.92 \\
\hline $0-8$ & 227 & 82.9 & 257 & 81.6 & 一 \\
\hline $10-24$ & 39 & 14.2 & 48 & 15.2 & - \\
\hline $26-40$ & 8 & 2.9 & 10 & 3.2 & - \\
\hline Total & 274 & 100.0 & 315 & 100.0 & - \\
\hline 60-69 Years & & & & & 0.46 \\
\hline $0-8$ & 72 & 72.7 & 304 & 77.4 & - \\
\hline $10-24$ & 23 & 23.2 & 70 & 17.8 & - \\
\hline $26-40$ & 4 & 4.1 & 19 & 4.8 & - \\
\hline Total & 99 & 100.0 & 393 & 100.0 & - \\
\hline 70-79 Years & & & & & 0.93 \\
\hline $0-8$ & 88 & 73.3 & 176 & 73.0 & - \\
\hline $10-24$ & 24 & 20.0 & 51 & 21.2 & - \\
\hline $26-40$ & 8 & 6.7 & 14 & 5.8 & - \\
\hline Total & 120 & 100.0 & 241 & 100.0 & - \\
\hline 80+ Years & & & & & 0.58 \\
\hline $0-8$ & 45 & 59.2 & 23 & 69.7 & 一 \\
\hline $10-24$ & 22 & 29.0 & 7 & 21.2 & 一 \\
\hline $26-40$ & 9 & 11.8 & 3 & 9.1 & - \\
\hline Total & 76 & 100.0 & 33 & 100.0 & - \\
\hline Overall & & & & & 0.80 \\
\hline $0-8$ & 432 & 75.9 & 760 & 77.4 & - \\
\hline $10-24$ & 108 & 19.0 & 176 & 17.9 & - \\
\hline 26-40 & 29 & 5.1 & 46 & 4.7 & - \\
\hline Total & 569 & 100.0 & 982 & 100.0 & - \\
\hline
\end{tabular}

ing) and reduced word-recognition abilities as a function of age. The hearing aid use data in Table 7 reflect these decreased auditory functions and abilities in that hearing aid use increased consistently as a function of age. For example, veterans' current use of hearing aids progressed from 2.5 to 5.5 to 12.0 to 24.2 percent across the four age groups with a similar pattern observed for the nonveterans. An interesting story from the data in Table $\mathbf{7}$ is the relation between those who had previous hearing aid use and those who currently used hearing aids. Collectively, 202 participants acknowledged prior hearing aid usage, whereas 128 participants were current hearing aid users. Thus, for unknown reasons, 74 participants were no longer wearing hearing aids and could represent unsuccessful hearing aid users. A more detailed account of the hearing aid use data is provided by Popelka et al. [26]. 
(a)

(b)

(c)

(d)

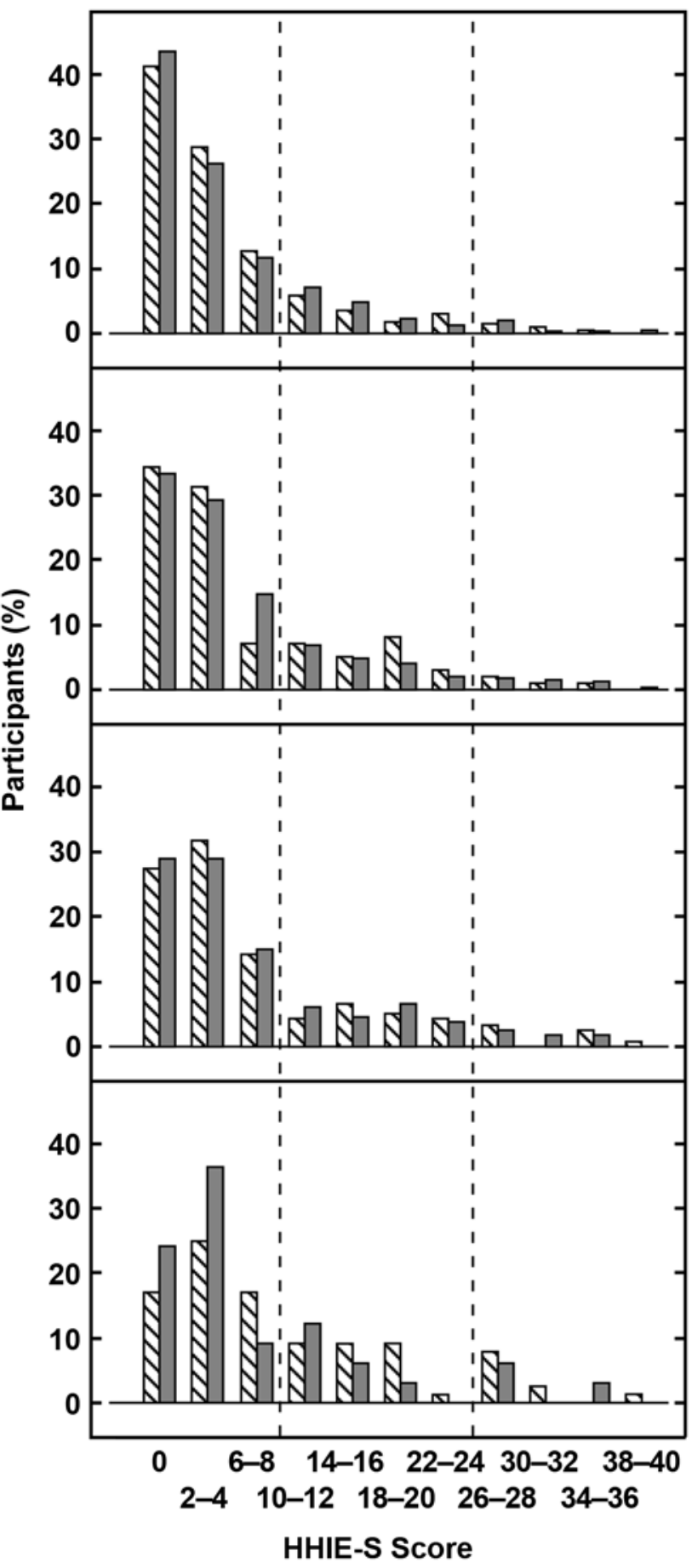

Figure 9.

Histograms showing percent of male participants in veteran (diagonal lines) and nonveteran (shaded) groups who had Hearing Handicap Inventory for the Elderly-Screening (HHIE-S) version scores in respective scoring bins in each of four age groups: (a) 48-59 yr, (b) 60-69 yr, (c) 70-79 yr, and (d) 80+ yr. Vertical dashed lines divide scoring range into three HHIE-S scoring categories that are detailed in Table 6.
Table 7.

Number and percentage of male nonveterans and veterans by age group and overall who had worn a hearing aid and who were wearing a hearing aid at time of study. Chi-square was used to generate $p$-values.

\begin{tabular}{|c|c|c|c|c|c|c|c|c|c|c|}
\hline \multirow{3}{*}{$\begin{array}{c}\text { Age/ } \\
\text { Ever Wore } \\
\text { Hearing Ai }\end{array}$} & \multicolumn{5}{|c|}{ Ever Worn Hearing Aid } & \multicolumn{5}{|c|}{ Now Wearing Hearing Aid } \\
\hline & \multicolumn{2}{|c|}{ Nonveteran } & \multicolumn{2}{|c|}{ Veteran } & \multirow{2}{*}{$\begin{array}{c}p- \\
\text { Value }\end{array}$} & \multicolumn{2}{|c|}{ Nonveteran } & \multicolumn{2}{|c|}{ Veteran } & \multirow{2}{*}{$\begin{array}{c}p- \\
\text { Value }\end{array}$} \\
\hline & $n$ & $\%$ & $n$ & $\%$ & & $n$ & $\%$ & $n$ & $\%$ & \\
\hline 48-59 Years & & & & & 0.57 & & & & & 0.56 \\
\hline Yes & 11 & 4.0 & 10 & 3.2 & - & 5 & 1.8 & 8 & 2.5 & - \\
\hline No & 263 & 96.0 & 307 & 96.8 & - & 269 & 98.2 & 309 & 97.5 & - \\
\hline 60-69 Years & & & & & 0.25 & & & & & 0.11 \\
\hline Yes & 14 & 13.7 & 39 & 9.8 & - & 10 & 9.8 & 22 & 5.5 & - \\
\hline No & 88 & 86.3 & 360 & 90.2 & - & 92 & 90.2 & 377 & 94.5 & - \\
\hline 70-79 Years & & & & & 0.08 & & & & & 0.48 \\
\hline Yes & 33 & 26.8 & 47 & 18.9 & - & 18 & 14.6 & 30 & 12.0 & - \\
\hline No & 90 & 73.2 & 202 & 81.1 & - & 105 & 85.4 & 219 & 88.0 & - \\
\hline 80+ Years & & & & & 0.46 & & & & & 0.53 \\
\hline Yes & 37 & 40.7 & 11 & 33.3 & - & 27 & 30.0 & 8 & 24.2 & - \\
\hline No & 54 & 59.3 & 22 & 66.7 & - & 63 & 70.0 & 25 & 75.8 & - \\
\hline Overall & & & & & 0.002 & & & & & 0.02 \\
\hline Yes & 95 & 16.1 & 107 & 10.7 & - & 60 & 10.2 & 68 & 6.8 & - \\
\hline No & 495 & 83.9 & 891 & 89.3 & - & 529 & 89.8 & 930 & 93.2 & - \\
\hline
\end{tabular}

\section{CONCLUSIONS}

Veterans and nonveterans in this study were equally likely to have a hearing loss in the auditory domains of pure tone thresholds, word recognition in quiet, and word recognition in a competing message. Likewise, the HHIE-S scores for the two participant groups were not significantly different. Overall, hearing aid use by veterans and nonveterans was significantly different, but when considered by age group, the differences were not significant. These findings were somewhat unexpected considering the opportunity for noise exposure that is present during military service. Note, however, that only 28 percent of the veterans reported their service roles as combat or combat support and the veterans included were from before the 1990-1991 Persian Gulf war.

\section{ACKNOWLEDGMENTS}

\section{Author Contributions:}

Study concept and design: C. M. Noe, R. H. Wilson, K. J. Cruickshanks. Acquisition of data: C. M. Noe, K. J. Cruickshanks, D. M. Nondahl, T. L. Wiley.

Analysis and interpretation of data: D. M. Nondahl, K. J. Cruickshanks, C. M. Noe, R. H. Wilson.

Drafting of manuscript: R. H. Wilson, C. M. Noe.

Critical revision of manuscript for important intellectual content:

R. H. Wilson, K. J. Cruickshanks, T. L. Wiley. 
Statistical analysis: D. M. Nondahl, K. J. Cruickshanks.

Obtained funding: C. M. Noe, R. H. Wilson.

Study supervision: C. M. Noe, K. J. Cruickshanks.

Financial Disclosures: The authors have declared that no competing interests exist.

Funding/Support: This material was based, in part, on work supported as a pilot project by the Seattle Epidemiology Research Information Center. Additionally, this work was supported by the Rehabilitation Research and Development Service, VA, through a Senior Research Career Scientist award, grant C2400S, to Dr. Wilson, and a National Institute on Aging award, grant R37AG011099, to Dr. Cruickshanks. Additional Contributions: We thank Rachel McArdle for her assistance with the statistical analyses. Portions of this article were presented at the annual meeting of the Association of VA Audiologists in Orlando, Florida (2010). The contents of this article do not represent the views of the National Institute on Aging, the National Institutes of Health, VA, or the U. S. Government.

Institutional Review: The study was approved by both the joint East Tennessee State University/VA Institutional Review Board (99-184e) and by the University of Wisconsin-Madison Institutional Review Board (2000-384). Informed consent was obtained during the auditory examination.

Participant Follow-Up: The authors do not plan to inform the participants of the publication of this study because of a lack of contact information.

\section{REFERENCES}

1. Bunch CC. Age variations in auditory acuity. Arch Otolaryngol. 1929;9(6):625-36.

2. Hinchcliffe R. The threshold of hearing as a function of age. Acoustica. 1959;3:303-8.

3. Goetzinger CP, Proud GO, Dirks D, Embrey J. A study of hearing in advanced age. Arch Otolaryngol. 1961;73:662-74. [PMID: 13706298]

4. Corso JF. Aging and auditory thresholds in men and women. Arch Environ Health. 1963;6:350-56. [PMID: 14023184]

5. Cooper JC, Owen JH. Audiologic profile of noise-induced hearing loss. Arch Otolaryngol. 1976;102(3):148-50. [PMID: 1267690]

6. Gates GA, Cooper JC Jr, Kannel WB, Miller NJ. Hearing in the elderly: The Framingham cohort, 1983-1985. Part I. Basic audiometric test results. Ear Hear. 1990;11(4):247-56. [PMID: 2210098]

7. Cruickshanks KJ, Wiley TL, Tweed TS, Klein BE, Klein R, Mares-Perlman JA, Nondahl DM. Prevalence of hearing loss in older adults in Beaver Dam, Wisconsin. The Epidemiology of Hearing Loss Study. Am J Epidemiol. 1998; 148(9):879-86. [PMID: 9801018]

8. Linton KL, Klein BE, Klein R. The validity of selfreported and surrogate-reported cataract and age-related macular degeneration in the Beaver Dam Eye Study. Am J Epidemiol. 1991;134(12):1438-46. [PMID: 1776618]
9. Klein R, Klein BE, Lee KE. Changes in visual acuity in a population. The Beaver Dam Eye Study. Ophthalmology. 1996;103(8):1169-78. [PMID: 8764783]

10. Nondahl DM, Cruickshanks KJ, Wiley TL, Tweed TS, Klein BE, Klein R. Interexaminer reliability of otoscopic signs and tympanometric measures for older adults. J Am Acad Audiol. 1996;7(4):251-59. [PMID: 8827919]

11. Wiley TL, Cruickshanks KJ, Nondahl DM, Tweed TS, Klein $\mathrm{R}$, Klein BE. Tympanometric measures in older adults. J Am Acad Audiol. 1996;7(4):260-68. [PMID: 8827920]

12. Ventry IM, Weinstein BE. The hearing handicap inventory for the elderly: A new tool. Ear Hear. 1982;3(3):128-34. [PMID: 7095321] DOI:10.1097/00003446-198205000-00006

13. Guidelines for manual pure-tone threshold audiometry. ASHA. 1978;20(4):297-301. [PMID: 656172]

14. Department of Veterans Affairs. Speech Recognition and Identification Materials, Disc 1.1 [CD]. Long Beach (CA): VA Medical Center; 1991.

15. Wilson RH, Zizz CA, Shanks JE, Causey JD. Normative data in quiet, broadband noise, and competing message for Northwestern University Test No. 6 by a female speaker. J Speech Hear Disord. 1990;55(4):771-78. [PMID: 2232756]

16. Tillman TW, Carhart R. An expanded test for speech discrimination utilizing CNC monosyllabic words. Northwestern University Auditory Test No. 6. SAM-TR-66-55. Tech Rep SAM-TR. 1966:1-12. [PMID: 5296571]

17. Mantel N. Chi-square tests with one degree of freedom; Extensions of the Mantel-Haenszel procedure. J Am Stat Assoc. 1963;58:690-700. DOI:10.2307/2282717

18. Specifications for audiometers. ANSI S3.6-1989. New York (NY): American National Standards Institute; 1989.

19. Goldstein DP. Hearing impairment, hearing aids and audiology. ASHA. 1984;26(9):24-35,38. [PMID: 6487402]

20. Jerger J, Jerger S, Pirozzolo F. Correlational analysis of speech audiometric scores, hearing loss, age, and cognitive abilities in the elderly. Ear Hear. 1991;12(2):103-9.

[PMID: 2065833]

DOI:10.1097/00003446-199104000-00004

21. Humes LE, Coughlin M, Talley L. Evaluation of the use of a new compact disc for auditory perceptual assessment in the elderly. J Am Acad Audiol. 1996;7(6):419-27. [PMID: 8972443]

22. Wiley TL, Cruickshanks KJ, Nondahl DM, Tweed TS. Self-reported hearing handicap and audiometric measures in older adults. J Am Acad Audiol. 2000;11(2):67-75. [PMID: 10685672]

23. Bess FH, Lichtenstein MJ, Logan SA, Burger MC. Comparing criteria of hearing impairment in the elderly: A functional approach. J Speech Hear Res. 1989;32(4):795-802. [PMID: 2532268] 
24. American Speech-Language-Hearing Association. Guidelines for audiologic screening. Rockville (MD): American Speech-Language-Hearing Association; 1997.

25. Lichtenstein MJ, Bess FH, Logan SA. Diagnostic performance of the hearing handicap inventory for the elderly (screening version) against differing definitions of hearing loss. Ear Hear. 1988;9:208-11. [PMID: 3169401] DOI:10.1097/00003446-198808000-00006

26. Popelka MM, Cruickshanks KJ, Wiley TL, Tweed TS, Klein BE, Klein R. Low prevalence of hearing aid use among older adults with hearing loss: The epidemiology of Hearing Loss Study. J Am Geriatr Soc. 1998;46(9):1075-78.

[PMID: 9736098]
Submitted for publication October 20, 2009. Accepted in revised form April 20, 2010.

This article and any supplementary material should be cited as follows:

Wilson RH, Noe CM, Cruickshanks KJ, Wiley TL, Nondahl DM. Prevalence and degree of hearing loss among males in Beaver Dam cohort: Comparison of veterans and nonveterans. J Rehabil Res Dev. 2010;47(6):505-20. DOI:10.1682/JRRD.2009.10.0169 
